Vol tammet ry i n I ow concent $r$ at i on of el ectrol yte supported by i oni c I at ex suspensi ons

\begin{tabular}{|l|l|}
\hline 著者 & $\begin{array}{l}\text { Aoki Koi chi J., Zhao Xi aoyu, Chen Ji ngyuan, } \\
\text { N shi um Toyohi ko }\end{array}$ \\
\hline $\begin{array}{l}\text { j our nal or } \\
\text { publ i cat i on ti tl e }\end{array}$ & Journal of El ect roanal yt i cal Chemi st ry \\
\hline vol ume & 697 \\
\hline page range & $5-9$ \\
\hline year & $2013-05$ \\
\hline URL & ht t p: //hdl . handl e. net /10098/9863 \\
\hline
\end{tabular}




\title{
Voltammetry in low concentration of electrolyte supported by ionic latex suspensions
}

\author{
Koichi J. Aoki* Xiaoyu Zhao, Jingyuan Chen, Toyohiko Nishiumi \\ Department of Applied Physics, University of Fukui, 3-9-1 Bunkyo, Fukui, 910-0017 \\ Japan
}

\section{Abstract}

Since ionic conductivity has a linear relation with the square of the number of charge, ionic latex particles with a huge number of the charge could provide high conductance. It is expected that addition of only a small amount of latex particles into voltammetric solution enhances the conductance so much that voltammograms can be measured, overcoming ohmic drop. Conductivity of latex suspensions of polystyrenepolystyrenesulfonic acid with volume fractions less than 0.02 , which were well deionized by centrifugation, was determined by ac-impedance at two parallel wire electrodes. Since the resistance was determined by the dependence of the in-phase component on the electrode distance, it did not include participation of electric double layers or adsorption of latex. The relationship between conductivity and a diffusion coefficient stated that the conductivity of the suspension was provided mainly by diffusion of latex particles with multiple charges rather than that of the counterion. The suspension with $\left[\mathrm{H}^{+}\right]=10^{-5} \mathrm{M}$, corresponding to $8.9 \times 10^{5}$ number $\mathrm{mm}^{-3}$, including hydrogen gas showed a voltammetric oxidation peak of hydrogen, whereas hydrochloric acid with $[\mathrm{HCl}]=10^{-5} \mathrm{M}$ showed a resistive current-potential curve.

\footnotetext{
* Corresponding author, e-mail: kaoki@u-fukui.ac.jp (K.J. Aoki), phone +81 77627 8665 , fax +81776278750
} 
key words: suspensions of latex particles; polystyrene-polystyrenesulfonic acid; ionic conductivity; ac impedance

\section{Introduction}

Acid with $z$ dissociated hydrogen ions, $\mathrm{H}_{z} \mathrm{~A}$, shows the molar conductivity of $\Lambda=$ $z \lambda_{\mathrm{H}}+\lambda_{\mathrm{A}}$, where $\lambda_{\mathrm{H}}$ and $\lambda_{\mathrm{A}}$ are molar conductivities of the hydrogen ion and the anion $\mathrm{A}$, respectively [1]. The Nernst-Einstein equation for ion $i$ relates the molar conductivity with the diffusion coefficient $D_{i}$ through

$$
\lambda_{i}=z u_{i} F=z^{2} D_{i} F^{2} / R T
$$

The ionic mobility, $u_{i}$ given by $z_{i} D F / R T$, means a steady-state speed of the ion with the charge $z e$ driven by the unit electric field intensity. The ion carries $z e$ charge to yield electric current. Therefore the molar conductivity includes the square of $z$. The $z^{2}$-dependence of the conductivity can be seen in a series of molar conductivities of $\mathrm{Li}^{+}$ (0.004 $\left.\mathrm{S} \mathrm{m}^{2} \mathrm{~mol}^{-1}\right), \mathrm{Ba}^{2+}(0.013), \mathrm{Fe}(\mathrm{CN})_{6}{ }^{3-}(0.030)$ and $\mathrm{Fe}(\mathrm{CN})_{6}{ }^{4-}(0.044)$ [2]. Suspended spherical polyelectrolytes like ionic latex have a huge number of $z$, and hence they may show extremely large conductivity. They could work as supporting electrolyte in voltammetry without adding excessive concentration of salt.

Ionic properties of latex suspensions are conductivity and $\zeta$-potential, which have been examined in the light of surface conductivity [3-12]. They have also been examined theoretically by combining the ion-transport equation with the Poisson equation [13-19]. Unfortunately, they have not yet been applied to voltammetry except for electrode reactions of counterions of the latex [20-23], to our knowledge. There are some difficulties in quantitatively evaluating roles of supporting electrolyte in ionic latex suspensions. Firstly, a value of $z$ is generally smaller than the stoichiometric number because of the behavior of weak acid depending on ionic environment. 
Secondly, evaluation of the conductance varies with adsorption and double layer effects [24,25], which have not often been taken into account [26,27].

We have developed a technique of determining reproducibly conductance of solution and electric double layer capacitance without the above complications [28]. The apparatus of the method is composed of two parallel wire electrodes with variable inter-electrode distance. When a part of a wire electrode is inserted into solution, there is no boundary between the electrode and insulating wall, which often causes irreproducible currents. Therefore there is no stray capacitor by incomplete shield of the wall. Since conductivity is evaluated by the slope of the conductance with the inter-electrode distance, double layer effects are largely eliminated. This paper deals with determining conductivity of suspensions of deionized polystyrene-sulfonic acid by use of the two wire electrodes in order to know the net charge of latex particles relevant to conductance. The conductivity will be demonstrated to be provided mainly by latex particles rather than the counterion. This property will be applied to voltammetry in low concentration of supporting electrolyte at normally sized electrodes [29-33] rather than at microelectrodes [34-44].

\section{Experimental}

\subsection{Chemicals}

Water used was ion-exchanged at first, distilled and then ion-exchanged again by an ultrapure water system, CPW-100 (Advantec, Tokyo). The conductometer of the water system showed that the resistivity of water was $18 \mathrm{M} \Omega \mathrm{cm}$. Styrene was distilled before the polymerization. Other chemicals were of analytical grade, and were used as received. 


\subsection{Synthesis of polystyrenesulfonate latex suspensions}

The polystyrene sulfonic acid latex was synthesized firstly by producing polystyrene microspheres a few micrometers in diameter [45], and secondly by polymerizing polystyrene sulfonate on the microspheres. A stabilizer, $1.5 \mathrm{~g}$ polyvinyl pyrrolidone, was dissolved in $100 \mathrm{~cm}^{3}$ 2-propanol in a round bottomed flask equipped with a mechanical stirrer and a reflux condenser. The solution was heated at $70^{\circ} \mathrm{C}$ and kept under a nitrogen atmosphere overnight. When $10 \mathrm{~cm}^{3}$ cold distilled styrene mixed with $30 \mathrm{~cm}^{3}$ 2-propanol including $0.15 \mathrm{~g}$ azoisobutyronitrile (AIBN) was added to the above solution, polymerization of styrene started. By keeping the solution at $70^{\circ} \mathrm{C}$ in the nitrogen atmosphere for one day, polystyrene microspheres were generated in suspension form. The suspension was diluted twice with water. A mixture of $0.0223 \mathrm{~g}$ sodium $p$-styrene sulfonate, $1.0 \mathrm{~cm}^{3}$ styrene and $0.0214 \mathrm{~g} \mathrm{AIBN}$ was added to the 100 $\mathrm{cm}^{3}$ suspension. The resulting suspension was stirred at $22{ }^{\circ} \mathrm{C}$ for $24 \mathrm{~h}$ under a nitrogen atmosphere, and then was heated at $75{ }^{\circ} \mathrm{C}$ for $8 \mathrm{~h}$ to copolymerize styrene with styrene sulfonate. The temperature was increased to $82^{\circ} \mathrm{C}$ for $16 \mathrm{~h}$ to complete the copolymerization.

Purification was carried out by addition of pure water to the suspension, by centrifugation, and by decantation. The centrifugation was made at $4600 \mathrm{~g}$ with a refrigerated centrifuge, SRX-201 (Tomy, Tokyo) for $50 \mathrm{~min}$. This process was repeated three times. Sodium ion in the suspension was replaced by hydrogen ion by adding $1 \mathrm{M}$ $\mathrm{HCl}$ to the suspension. The ion-exchanged (from $\mathrm{Na}^{+}$to $\mathrm{H}^{+}$) suspension was stirred gently for $14 \mathrm{~h}$. $\mathrm{NaCl}$ and $\mathrm{HCl}$ were removed by six iterative steps of centrifugation and decantation.

\subsection{Measurements and instrumentation}


Electrodes were two platinum wires $0.1 \mathrm{~mm}$ in diameter arranged in parallel. The wire was twisted around on a tungsten wire for an electric lead. One of the wires was fixed vertically with a beam, and the other was mounted on an optical $x y z$ positioner so that the distance, $d$, between the two wires and the immersion length of the wire, $L$, were adjusted, as illustrated in Fig. 1. Values of $d$ and $L$ were read through an optical microscope. A typical value of $L$ was $4 \mathrm{~mm}$.

The potentiostat was Compactstat (Ivium, Netherlands), equipped with a lock-in amplifier. Applied alternating voltage was $10 \mathrm{mV}$ in amplitude. Solution or suspension was deaerated by nitrogen gas for $15 \mathrm{~min}$ before each electrochemical measurement. Delay of the potentiostat was examined by the process same as in the previous report [28]. Errors of detected phase angles in the potentiostat were estimated by use of a series combination of a film capacitor $0.2 \mu \mathrm{F}$ and a carbon resistance $1 \mathrm{M} \Omega$. When the ratio of out of phase component to in-phase one was less than 0.001 , the out of phase was observed to be estimated to be lower values.

Digital optical photomicrographs of the latex particles were obtained with a video microscope, VMS-1900 (Scalar), and were transferred to a PC using a MPG capture board, with which the size distribution and particle-dispersion were determined. The $\mathrm{pH}$ meter was MP225 (Mettler Toledo).

A conductometer was home-made by binding two platinum disk electrodes flush with a polytetrafluoroethylene plate. The two disks had center-to-center separation, 5.5 $\mathrm{mm}$. Alternating voltage with $1 \mathrm{kHz}$ and $10 \mathrm{mV}$ amplitude was applied to the electrodes. The in-phase component of the responding current was calibrated with several concentrations of $\mathrm{KCl}$ solutions ranging from 0.001 to $0.1 \mathrm{M}$ to determine the cell constant.

Hydrogen gas was bubbled in the suspension or aqueous solution for 15 minutes. Voltammetry of hydrogen gas was observed at the Pt disk electrode $1.6 \mathrm{~mm}$ in diameter. The reference electrode was $\mathrm{Ag} \mid \mathrm{Ag}_{x} \mathrm{O}$, which contained no ionic solution. It was 
prepared by immersing a silver wire in the solution of concentrated sulfuric acid and concentrated hydrogen peroxide at $7: 1$ volume ratio for ten min. The equilibrium potential of this electrode was $0.15 \pm 0.01 \mathrm{~V}$ vs. $\mathrm{Ag} \mid \mathrm{AgCl}$ in water. It varied by less than $10 \mathrm{mM}$ for the voltammetric runs.

\section{Results and Discussion}

\subsection{Properties of latex suspensions}

The latex particles were spherical with a common diameter, $(2 r=3.33 \pm 0.10) \mu \mathrm{m}$, which was an average of 12 sampled particles by the optical microscope in the wet state. The number concentration of particles in the suspension was determined by drying and weighing a sample volume of the suspension. The weight was converted into the volume by use of the density of polystyrene $\left(1.05 \mathrm{~g} \mathrm{~cm}^{-3}\right)$ on the assumption that the polystyrene sulfonate film was very thin. A stock suspension had number concentration, $9.0 \times 10^{11}$ particles per $\mathrm{dm}^{3}$ or volume fraction, $\phi=0.017$.

Amount of hydrogen ion on the latex particle were determined by titration with $\mathrm{NaOH}$ under monitoring of the conductivity (see supporting material). The conductivity decreased initially with addition of $\mathrm{NaOH}$ because the molar conductivity of sodium ion is smaller than that of hydrogen ion. Further addition of $\mathrm{NaOH}$ over the equivalent point increased the conductivity, because of extra amounts of $\mathrm{Na}^{+}$and $\mathrm{OH}^{-}$. From the turning point of the titration curve, we determined $1.1 \times 10^{-15} \mathrm{~mol} \mathrm{SO}_{3}^{-}$or $n=6.6 \times 10^{8} \mathrm{SO}_{3}^{-}$ molecules per one particle. If $\mathrm{SO}_{3}{ }^{-}$moiety is distributed uniformly on the latex surface, one $\mathrm{SO}_{3}{ }^{-}$occupies $0.052 \mathrm{~nm}^{2}=(0.23 \mathrm{~nm})^{2}$. Since this is smaller than the diameter of a water molecule $(0.31 \mathrm{~nm})$ estimated by the molar volume, $\mathrm{SO}_{3}{ }^{-}$moiety ought to take multi-layered form on the latex surface or to be distributed in the core. We define the titrated concentration of $\mathrm{SO}_{3}{ }^{-}$in the latex suspension at the volume fraction $\phi$ to be 
$c_{\mathrm{SO} 3}=\frac{\phi n}{(4 / 3) \pi r^{3} N_{\mathrm{A}}}$

Then we can obtain the completely dissociated ionic concentration through $c_{\mathrm{SO} 3}=\phi$ $\times(0.056 \mathrm{M})$ in the present case.

In order to estimate a trace amount of released ions in suspensions, we prepared the deionized suspension at $\phi=0.0039$, which corresponds to $c_{\mathrm{SO}}=0.2 \mathrm{mM}$, by four iterative steps of centrifugation-redispersion. The supernatant showed the resistivity, 0.6 $\mathrm{M} \Omega \mathrm{cm}$. The deionized water used here showed the resistivity, $3 \mathrm{M} \Omega \mathrm{cm}$. Therefore, the supernatant contained ions five times as much as the deionized water did.

\subsection{Ac impedance}

The cell in Fig 1 was filled with the well-deionized suspension for known concentration of the latex. Ac impedance between the two electrodes was obtained at zero dc voltage. Figure 2 shows the Nyquist plot, i.e., the out of phase, $Z_{2}$, vs. the in-phase, $Z_{1}$. The plot does not take a conventional semi-circle because of a polarized interface [28]. A line in Nyquist plots represents a typical property of the constant phase element, which is expressed by $-Z_{2} /\left(Z_{1^{-}}-R_{\mathrm{S}}\right)=\tan (\pi \alpha / 2)$ at a constant parameter, $\alpha$ [46-49], where $R_{\mathrm{S}}$ is solution resistance. The value of $\alpha$ for the line in Fig. 2 is 0.95 . Since $\alpha=1$ and 0 mean the capacitive control and the resistive control, respectively, the impedance is mostly the capacitive control. The Nyquist plot for dodecylbenzenesulfonate was similar to that of the styrene sulfonate suspension.

Solution resistance has been conventionally determined from a value of $Z_{1}$ at extremely high frequencies [50]. Practically, it is the extrapolated value of $Z_{1}$ for $Z_{2} \rightarrow 0$. The extrapolated values, $R_{\mathrm{s}}$, were obtained for several distances between two electrode, $d$, and are plotted against $\log (d / a-1)$ in Fig. 3, where $a$ is the radius of the wire electrode. The expression for the solution resistance of monovalent electrolyte between 
two parallel wires $L$ in length has been derived on the basis of the electrode geometry from the solution of the two-dimensional Laplace equation [28], and is given approximately by

$$
R_{\mathrm{s}}=0.916 \frac{\log (d / a-1)}{L c \Lambda}
$$

where $A$ is the molar conductivity of the salt, and $c$ is the concentration of the salt. Values of $R_{\mathrm{S}}$ had a linear relationship with $\log (d / a-1)$, exhibiting a positive value of the intercept at $\log (d / a-1)=0$ or $d=2 a$ (Fig. 3). Similar variation was found for sodium $p$-styrene sulfonate (open circles). Since the values at the intercept $(10.7 \mathrm{k} \Omega)$ results from properties of the interface (at $d=2 a$ ), our concern is directed only to the slope of the linearity. According to Eq. (3), the slope is equal to the $0.916 / L c \Lambda$. It was independent of frequency in the range of $1 \mathrm{~Hz}<f<5 \mathrm{kHz}$.

Values of the resistivity, $\rho$, determined from the slope were plotted against concentrations in the logarithmic scale in Fig. 4. They fell on a line with the unity slope, i.e. $\rho=k / c \mathrm{SO} 3$ for a constant $k$. The inverse proportionality was valid in the concentration range with two orders of magnitude, independent of capacitive component of the electric double layer. The value of $\rho\left(=10^{4.4} \Omega \mathrm{mm}\right)$ at $c_{\mathrm{SO} 3}=1 \mathrm{mM}$ in Fig. 4 implies that the molar conductivities would be $\Lambda\left(=1 / \rho c \mathrm{SO}_{3}\right)=0.039 \mathrm{~S} \mathrm{~m}^{2}$ $\mathrm{mol}^{-1}$ if all the hydrogen ion is released from the latex. This value is similar to the limiting ionic conductivity of hydrogen ion $\left(0.035 \mathrm{~S} \mathrm{~m}^{2} \mathrm{~mol}^{-1}\right)$ [2]. The similarity implies that all the hydrogen ions might be released from the latex surface against the electrostatically attractive force.

We take into account a role of the charged latex particle in the conductivity because the $z^{2}$-dependence in Eq. (1) is significant to the conductance. All the $\mathrm{SO}_{3} \mathrm{H}$ moieties (the number of $n$ moeties in one particle) cannot be dissociated into $\mathrm{SO}_{3}{ }^{-}$and $\mathrm{H}^{+}$because of the ionic interaction. We define the conductivity of the latex suspension 
per $N_{\mathrm{A}}$ latex particles as the sum of the molar conductivity of $z$ free hydrogen ions, $z \lambda_{\mathrm{H}}$, and the conductivity of $N_{\mathrm{A}}$ sulfonic latex particles, $\lambda_{\mathrm{L}}$ :

$$
\Lambda_{\mathrm{L}}=z \lambda_{\mathrm{H}}+\lambda_{\mathrm{L}}
$$

Here, we neglected effects of difference between concentration and activity because activity coefficients of hydrogen ion was at most 0.97 , according to the Debye-Hückel limiting law. When Eq. (1) for hydrogen ion and the latex particle are inserted into Eq. (4), we obtain

$$
\Lambda_{\mathrm{L}}=\left(F^{2} / R T\right)\left(z D_{\mathrm{H}}+z^{2} D_{\mathrm{L}}\right)
$$

By use of the Stokes-Einstein equation for $D_{\mathrm{L}}$, we estimate $D_{\mathrm{L}}=1.5 \times 10^{-9} \mathrm{~cm}^{2} \mathrm{~s}^{-1}$ for the sphere $3.3 \mu \mathrm{m}$ in diameter in water. Inserting the values of $D_{\mathrm{L}}$ and $D_{\mathrm{H}}\left(=9.3 \times 10^{-5} \mathrm{~cm}^{2}\right.$ $\mathrm{s}^{-1}$ ) and the experimental value of $\Lambda_{\mathrm{L}}$ into Eq. (5), we evaluated $z=6.8 \times 10^{6}$ by solving the quadratic equation. Since the ratio, $z^{2} D_{\mathrm{L}} /\left(z D_{\mathrm{H}}+z^{2} D_{\mathrm{L}}\right)$, is 0.99 , the conductance is caused mainly by the charge of the latex core rather than that of hydrogen ions.

The value of $z / n$ is $0.010_{3}$, indicating that only $1.0_{3} \%$ of sulfonic ion is survived as dissociated acid, the other being in the neutral form of $-\mathrm{SO}_{3} \mathrm{H}$. The value, $e z$, is the net charge of one latex particle in the deionized suspension. The charge density $\left(e z /\left(4 \pi r^{2}\right)\right)$ is $3 \mu \mathrm{C} \mathrm{cm}^{-2}$ if the charge is distributed uniformly on the latex surface. Since this value corresponds to the charge density of electric double layer at $\pm 0.1 \mathrm{~V}[51]$, it is not unusual. The surface area occupied by one $-\mathrm{SO}_{3}{ }^{-}$is $5.1 \mathrm{~nm}^{2}=(2.6 \mathrm{~nm})^{2}$, which can be acceptable for keeping the electric stability without large interaction.

Impurity of ions in the suspensions might enhance unexpectedly the conduction because of enhancement of the dissociation. Conductance of a supernatant of the suspension is a measure of impurity of ion, which was used for the ion exchange process. The Nyquist plot of the suspension is shown in Fig. 2(b), exhibiting too low ionic concentration to generate double layer capacitance. The resistivity was one-fifth that of pure water, indicating negligible concentration of impurity. Further confirmation 
was made through the $\mathrm{pH}$ variation with iterative numbers of the dispersion-centrifugation steps, as is shown in Fig. 5. Values of $\mathrm{pH}$ increased from the strong acid of $-\mathrm{SO}_{3} \mathrm{H}$ with an increase the iterative centrifugation, and reached 7 for pure water at the fifth iteration. Consequently, ionic impurity has no effect on the conductivity.

A value of $\mathrm{pH}$ is the other measure of impurity because salts dissociate sulfonic acid on the latex into hydrogen ion. When a $\mathrm{pH}$ meter was dipped into the suspensions, the $\mathrm{pH}$ values decreased gradually, as is shown in Fig. 6. Since no time variation of $\mathrm{pH}$ was found in hydrochloride solution of $\mathrm{pH} \mathrm{4.7,} \mathrm{the} \mathrm{decrease} \mathrm{in} \mathrm{Fig.} 6$ is ascribed to leakage of $\mathrm{KCl}$ from the reference electrode of the $\mathrm{pH}$ meter. Indeed, deliberate addition of $\mathrm{KCl}$ solution to the suspension decreased $\mathrm{pH}$ values more rapidly than the decrease in Fig. 6. The long term immersion of the $\mathrm{pH}$ meter made $\mathrm{pH}$ values tend to the corresponding value of the loaded concentration of $\mathrm{SO}_{3}{ }^{-}$(dashed line by the titration). The values of $\mathrm{pH}$ in Fig. 5 were those immediately after the immersion of the $\mathrm{pH}$ meter. The initial value of $\mathrm{pH}$ was 6.5 , whereas $\left[\mathrm{H}^{+}\right]$by the conductivity was $2 \mu \mathrm{M}\left(\left[-\mathrm{SO}_{3}{ }^{-}\right] z / n\right.$ $=0.2 \mathrm{mM} \times 1.0_{3} \%$ ). The value of $\left[\mathrm{H}^{+}\right]$in the latter is ten times larger than the former because conductometry facilitates the dissociation kinetics. pH Values in suspensions have ambiguity of representing activity of immobilized hydrogen ion or mobilized one.

\subsection{Voltammetry in suspensions}

A conclusion in the previous section is that the suspension of $\phi=0.017$ or $c_{\mathrm{SO} 3}=$ $1 \mathrm{mM}$ disperses $10^{-5} \mathrm{M}$ hydrogen ion. In other words, only $1 \%$ of sulfonic acid is dissociated. However, the conductivity is 100 times higher than that of $10^{-5} \mathrm{M}$ hydrogen ion. This fact can be applied to voltammetry in low concentration of supporting electrolyte. An ionic redox species is not suitable for this application because it also work as supporting electrolyte. Since reference electrodes such as $\mathrm{Ag} \mid \mathrm{AgCl}$ or 
$\mathrm{Hg} \mid \mathrm{Hg}_{2} \mathrm{Cl}_{2}$ increase concentration of chloride ion in solution through leakage, as is seen in Fig. 6, we used $\mathrm{Ag} \mid \mathrm{Ag}_{x} \mathrm{O}$ reference electrode without including salt. The $\mathrm{Ag} \mid \mathrm{Ag}_{x} \mathrm{O}$ reference electrode exhibited empirically a steady potential difference during a voltammetric time scale.

Figure 7 shows voltammograms of the oxidation of hydrogen gas after the gas was bubbled in (a) $c_{\mathrm{SO} 3}=1 \mathrm{mM}$ suspension $\left(\left[\mathrm{H}^{+}\right]=1 \mathrm{mM} \times 1 \%\right.$ ) and (b) $10^{-5} \mathrm{M} \mathrm{HCl}$ solution. The oxidation peak was observed in the suspension (a), whereas the $\mathrm{HCl}$ solution showed a resistive current-voltage curve (b). Although concentration of hydrogen ion is common, the former has lower conductance than the latter. The appearance of the peak is an evidence of the high conductivity supported by the latex particle. The peak current was proportional to the square-root of the scan rate, as is shown in Fig. 8. Therefore it should be mostly controlled by diffusion of hydrogen gas except for a suppression of the current by solution resistance. The diffusion-controlled current of hydrogen gas has been expressed by [52]

$I_{\mathrm{p}}=2.36 \times 0.446 A F \mathrm{c} * \sqrt{D v F / R T}$

where $A$ is the area of the electrode, and $D$ is the diffusion coefficient of $\mathrm{H}_{2}$. Here, the coefficient 2.36 results from the insufficient concomitant two-electron reaction [52]. By use of the data, $c^{*}=0.50 \mathrm{mM}$ and $D=4.6 \times 10^{-5} \mathrm{~cm}^{2} \mathrm{~s}^{-1}[52]$, the observed peak current was $20 \%$ of the calculated one. The decrease may be caused not only by apparent decrease in the scan rate owing to the ohmic potential shift $[29,30]$ but also by the validity of 2.36 in lower concentration of supporting electrolyte.

\section{Conclusions}

The conductivity of the suspension of the deionized polystyrene-sulfonic acid latex is provided mainly by diffusion of latex particles with multiple charges rather than that 
of counterions. The value of the conductivity is close to that of hydrogen ion if there was $100 \%$ dissociation from the latex. Most (99\%) hydrogen ions are immobilized on the latex not to contribute to the conduction, whereas only $1 \%$ participate in the conduction. On the contrary, most of hydrogen ions in equilibrium are immobilized so that the $\mathrm{pH}$ of the suspension is 6.5 .

Accurate determination of the conductivity of the latex suspensions requires exclusion of electric double layers effects such as adsorption and electrically capacitive components. The present method of varying distance between wire electrodes satisfies this requirement.

Low concentration of latex suspended ion works as voltammetric supporting electrolyte. The net concentration of latex suspension is at least 100 times smaller than that of monovalent ions, because the conductivity is provided mainly by the latex particles with huge values of $z$.

\section{Acknowledgement}

This work was financially supported by Grants-in-Aid for Scientific Research (Grants 22550072) from the Ministry of Education in Japan.

\section{References}

[1] P.W. Atkins, Physical Chemistry, Sixth Ed. Oxford University Press, Oxford, 1998, p. 738.

[2] P.W. Atkins, Physical Chemistry, Sixth Ed. Oxford University Press, Oxford, 1998, p. 948.

[3] C.F. Zukoski, D.A. Saville, J. Colloid Interface Sci. 107 (1985) 322.

[4] C.F. Zukoski, D.A. Saville, J. Colloid Interface Sci. 114 (1986) 32. 
[5] C.F. Zukoski, D.A. Saville, J. Colloid Interface Sci. 115 (1987) 422.

[6] R.J. Hill, D.A. Saville, J. Colloid Interface Sci. 263 (2003) 478.

[7] M. Rasmusson, S. Wall, J. Colloid Interface Sci. 209 (1999) 327.

[8] D. Hessinger, M. Evers, T. Palberg, Phys. Rev. E 61 (2000) 5493.

[9] P. Wette, H.J. Schope, T. Palberg, Colloids Surf. A 222 (2003) 311.

[10] M. Minor, A.J. van der Linde, J. Lyklema, J. Colloid Interface Sci. 203 (1998) 177.

[11] M. Minor, H.P. van Leeuwen, J. Lyklema, J. Colloid Interface Sci. 206 (1998) 397.

[12] M. Minor, H.P. van Leeuwen, J. Lyklema,Langmuir, 15 (1999) 6677.

[13] I. Sogami, N. Ise, J. Chem. Phys. 81 (1984) 6320.

[14] C.S. Mangelsdorf,L.R. White, J. Chem. Soc. Faraday Trans. 86 (1990) 2859.

[15] R.W. O'Brien, L.R. White, J. Chem. Soc., Faraday Trans. 2, 77 (1978) 1607.

[16] R.J. Hill, D.A. Saville, J. Colloid Interface Sci. 268 (2003) 230.

[17] M. Rasmusson, B.E. Mellander, J. Colloid Interface Sci. 209 (1999) 312.

[18] O. El-Gholabzouri, M. A. C.-Vílchez, R. H.-Álvarez, J. Colloid Interface Sci. 261 (2003) 386.

[19] M.L. Jiménez, F.J. Arroyob, F. Carriquec, A.V. Delgado, J. Colloid Interface Sci. $316(2007) 836$.

[20] J.M. Roberts, P. Linse, J.G. Osteryoung, Langmuir 14 (1998) 204.

[21] J.M. Roberts, J.J. O'dea, J.G. Osteryoung, Anal. Chem. 70 (1998) 3667.

[22] K. Aoki, T. Lei, Electrochemistry Commun.1 (1999) 101.

[23] K. Aoki, C. Wang, Langmuir, 17 (2001) 7371.

[24] K. Aoki, T. Li, J. Chen, T. Nishiumi, J. Electroanal. Chem. 613 (2008) 1.

[25] T. Li, K. Aoki, J. Chen, T. Nishiumi, J. Electroanal. Chem. 633 (2009) 319.

[26] R. Roldán-Toro, J.D. Solier, J. Colloid Interface Sci. 274 (2004) 76.

[27] F. J. Arroyo, F. Carrique, T. Bellini, A. V. Delgado, J. Colloid Interface Sci. 210 (1999) 194.

[28] K. Aoki, Y. Hou, J, Chen, T, Nishiumi, J. Electroanal. Chem. 689 (2013) 124. 
[29] E.J.F. Dickinson, J.G. Limon-Petersen, N.V. Rees, R.G. Compton, J. Phys. Chem. C 113 (2009) 11157.

[30] J.G. Limon-Petersen, E.J.F. Dickinson, S.R. Belding, N.V. Rees, R.G. Compton, J. Electroanal. Chem. 650 (2010) 135.

[31] Y. Wang, E.O. Barnes, E. Laborda, A. Molina, R.G. Compton, J. Electroanal. Chem. $673(2012) 13$.

[32] D. Aguilar, C. Parat, J. Galceran, E. Companys, J. Puy, L. Authier, M. PotinGautier, J. Electroanal. Chem. http://dx.doi.org/10.1016/j.jelechem.2012.11.010.

[33] M. Rimboud, K. Charreteur, V. Sladkov, C. Elleouet, F. Quentel, M. L'Her, J. Electroanal. Chem. 636 (2009) 53.

[34] W. Hyk, Z. Stojek, Anal. Chem. 77 (2005) 6481.

[35] C. Amatore, A. Oleinick, I. Svir, Anal. Chem. 80 (2008) 7947.

[36] M. Ciszkowska, Z. Stojek, J. Electroanal. Chem. 466 (1999) 129.

[37] M. B. Rooney, D. C. Coomber, A. M. Bond, Anal. Chem. 72 (2000) 3486.

[38] M.F. Bento, L.Thouin, C. Amatore, M.I. Montenegro, J. Electroanal.Chem. 443 (1998) 137.

[39] K.B. Oldham, J. Electroanal. Chem. 237 (1987) 303.

[40] K. Aoki, A. Baars, A. Jaworski, J. Osteryoung, J. Electroanal. Chem. 472 (1999) 1.

[41] M.J. Patys, Z. Stojek, M. Bos, W.E. van der Linden, J. Electroanal. Chem. 383 (1995) 105.

[42] Y. Zhang, B. Zhang, H.S. White, J. Phys. Chem. B 110 (2006) 1768.

[43] M. J. Pena, M. Fleischmann, N. Garrard, J. Electroanal. Chem.220 (1987) 31.

[44] Y. Liu, Q. Zhang, S. Chen, Electrochim. Acta 55 (2010) 8280.

[45] H. Chen, J. Chen, K. Aoki, T. Nishiumi, Electrochim. Acta 53 (2008) 7100.

[46] A. Lasia, in: R.E. White, B.E. Conway, J.O’M. Bockris (Eds.), Modern Aspects of Electrochemistry, 32, Kluwer Academic/Plenum Publishers, New York, 1999, p. 143. 
[47] L. Nyikos, T. Pajkossy, Electrochim. Acta 30 (1985) 1533.

[48] G.J. Brug, A.L.G. Van Den Eeden, M. Sluyters-Rehbach, J.H. Sluyters, J.

Electroanal. Chem. 176 (1984) 275.

[49] P. Zoltowski, J. Electroanal. Chem. 443 (1998) 149.

[50] A.J. Bard, L.R. Faulkner, Electrochemical Methods; Fundamentals and Applications, Second edition, Wiley, 2001, pp. 384-386.

[51] D.C. Grahame, Chem. Rev. 41 (1947) 441.

[52] K. Aoki, H. Toda, J. Yamamoto, J. Chen, T. Nishiumi, J. Electroanal. Chem. 668 (2012) 83. 